\title{
Use of class pedotransfer functions based on texture and bulk density of clods to generate water retention curves
}

\author{
A. Bruand ${ }^{1, *}$, P. Pérez Fernández ${ }^{2,3} \& \mathrm{O}$ Duval $^{2}$
}

\begin{abstract}
Water retention properties of 219 horizons were measured in Cambisols, Luvisols and Fluvisols, mainly from the Paris basin. We derived class pedotransfer functions (class PTFs) based on texture alone and in a second stage class PTFs based on classes combining texture and clod bulk density. The performance of these two types of PTFs were discussed at -330 and $-15000 \mathrm{hPa}$ water potential on an independent set of 221 horizons. Results showed that PTFs based on sets grouped by texture and clod bulk density provide estimates with an accuracy that is (i) greater than with class PTFs based on texture alone, and (ii) similar to the estimation accuracy recorded with continuous PTFs. As a consequence, the lack of interest in class PTFs should be reconsidered to bridge the gap between the available basic soil data and hydraulic properties which are generally missing, particularly when pertinent soil characteristics can be derived from the data available in soil databases. The two types of class PTFs providing gravimetric water contents at seven water potentials ranging from -10 to $-15000 \mathrm{hPa}$ were converted to volumetric water content using the soil bulk density. Finally, the parameters of van Genuchten's water retention curve model were computed for every class PTF.
\end{abstract}

Keywords: Soil horizon classification, water retention, porosity, structure

\section{INTRODUCTION}

$\mathrm{W}$ ater retention properties of representative soil horizons of France have been studied for several years in order to test the validity of pedotransfer functions (PTFs) that can be found in the literature. Bastet et al. (1999) evaluated PTFs that predict points of the water retention curve and others that predict the parameters of a mathematical model fitting the water retention curve. Their results showed that performance of the tested PTFs varied according to the pedological origin of the soils. Generally, the best performances were recorded with PTFs established on soils showing many similarities in parent material and pedogenesis. This is in agreement with Wösten et al. (2001) who concluded that PTFs should not be used to make predictions for soils that are outside the range of soils used to derive the PTFs. Bastet et al. (1999) showed also that the performance of tested PTFs was not related to the number or type of basic soil characteristics that were used as predictors. Simple PTFs like those of Bruand et al. (1996)

${ }^{1}$ ISTO, UMR CNRS-UO 6113, Université d'Orléans, Géosciences, BP 6759, 45067 Orléans cedex 2, France. ${ }^{2}$ INRA, Unité de Science du Sol, Centre de Recherche d'Orléans, BP 20619, 45166 Olivet cedex, France. ${ }^{3}$ Universidade de Santiago de Compostela, Escuela Politecnica Superior, Campus Universitario, 27002 Lugo, Spain.

*Corresponding author. Fax: 33 (0) 23841 7308. E-mail: Ary.Bruand@ univ-orleans.fr performed as well as the more complex PTF of Vereecken et al. (1989).

Since the water retained at a particular water potential is related to both the nature and arrangement of the elementary soil particles, most PTFs use particle size distribution, organic carbon content and bulk density as predictors in the regression equations (Wösten et al. 2001). However, these estimators are not independent, bulk density being related to particle size distribution and organic carbon content. On the other hand, many PTFs use soil characteristics that are expressed both on a mass basis (particle size distribution, organic carbon content) and on a volume basis (bulk density, volumetric water content at a particular water potential). It is more consistent to use the same reference system for the estimators and predicted characteristics.

Besides continuous pedotransfer functions that enable the estimation of the parameters of models of the water retention curve (Rawls et al. 1992; Minasmy et al. 1999; Wösten et al. 2001), there are class pedotransfer functions (class PTFs) that receive little attention because their accuracy is considered to be limited (Wösten et al. 1995). Class pedotransfer functions provide average water contents at particular water potentials or one average water retention curve for each texture class. However, due to the range in particle size distribution, clay mineralogy (Leij et al. 1999; 
Wösten et al., 1999), organic matter content and structural development within each texture class, water retention properties for individual soils can vary considerably. Despite their possible inaccuracies, class PTFs are easy to use because they require little soil information and are well adapted to prediction of water retention properties over large areas (Wösten et al. 1995; Lilly et al. 1999; Wösten et al. 1999).

In this article, we derived class PTFs based on texture alone; then, in a second stage, we derived class PTFs based on classes combining texture and clod bulk density. Clod bulk density was preferred to horizon bulk density because the latter includes macropores that do not intervene in water retention and vary in tilled topsoils with time and management. Accuracies of the two types of class PTFs were compared. We showed that taking both texture and clod bulk density into account leads to an increase in prediction accuracy of the gravimetric water content. Applications in agronomy and hydrology require the volumetric water content, so the gravimetric water content was converted into volumetric water content using the horizon bulk density. Finally, the parameters of the van Genuchten's water retention curve model (van Genuchten 1980) were computed for each class PTF.

\section{MATERIALS}

The soils studied were Cambisols, Luvisols and Fluvisols (ISSS Working Group RB 1998), mainly from the Paris basin with some from the western coastal marshlands and from the Pyrenean piedmont plain. The class PTFs were derived from a set of 219 horizons comprising 58 A horizons (54 ploughed), $16 \mathrm{E}$ horizons, $98 \mathrm{~B}$ horizons and $47 \mathrm{C}$ horizons. Another set of 221 horizons was used to test the proposed class PTFs. These horizons comprised 29 A horizons (23 ploughed), $15 \mathrm{E}$ horizons, $119 \mathrm{~B}$ horizons and

$58 \mathrm{C}$ horizons. The soils developed on a large range of parent materials (Table 1). For the set of horizons used to establish the PTFs and according to the FAO triangle of textures, texture was very fine (VF) for 22 horizons, fine $(\mathrm{F})$ for 42 horizons, medium fine (MF) for 62 horizons, medium (M) for 69 horizons and coarse (C) for 24 horizons (Figure 1a, Table 2). For the set of horizons used to test the PTFs, texture was $\mathrm{VF}$ for 25 horizons, $\mathrm{F}$ for 105 horizons, MF for 39 horizons, $\mathrm{M}$ for 35 horizons and $\mathrm{C}$ for 17 horizons (Figure 1b).

\section{METHODS}

The horizons were sampled in winter when the soil was near to field capacity. Undisturbed samples $100-1000 \mathrm{~cm}^{3}$ in volume were collected and stored at $5^{\circ} \mathrm{C}$ in sealed plastic containers to reduce biological activity and to avoid water

Table 1. Number of soil horizons per type of parent material.

\begin{tabular}{lc}
\hline Parent material & $\begin{array}{c}\text { Number } \\
\text { of } \\
\text { horizons }\end{array}$ \\
\hline Horizons used to derive the class pedotransfer functions $(n=219)$ & 46 \\
Marls and limestones & 2 \\
Clayey materials resulting from weathering & 28 \\
Old alluvium (river terraces) & 24 \\
Recent alluviums & 13 \\
Colluviums & 106 \\
Aeolian materials & \\
& \\
Horizons used to test the class pedotransfer functions $(n=221)$ & 97 \\
Marls and limestones & 37 \\
Clayey materials resulting from weathering & 6 \\
Old alluvium (river terraces) & 23 \\
Recent alluviums & 14 \\
Colluviums & 44 \\
Aeolian materials & \\
\hline
\end{tabular}
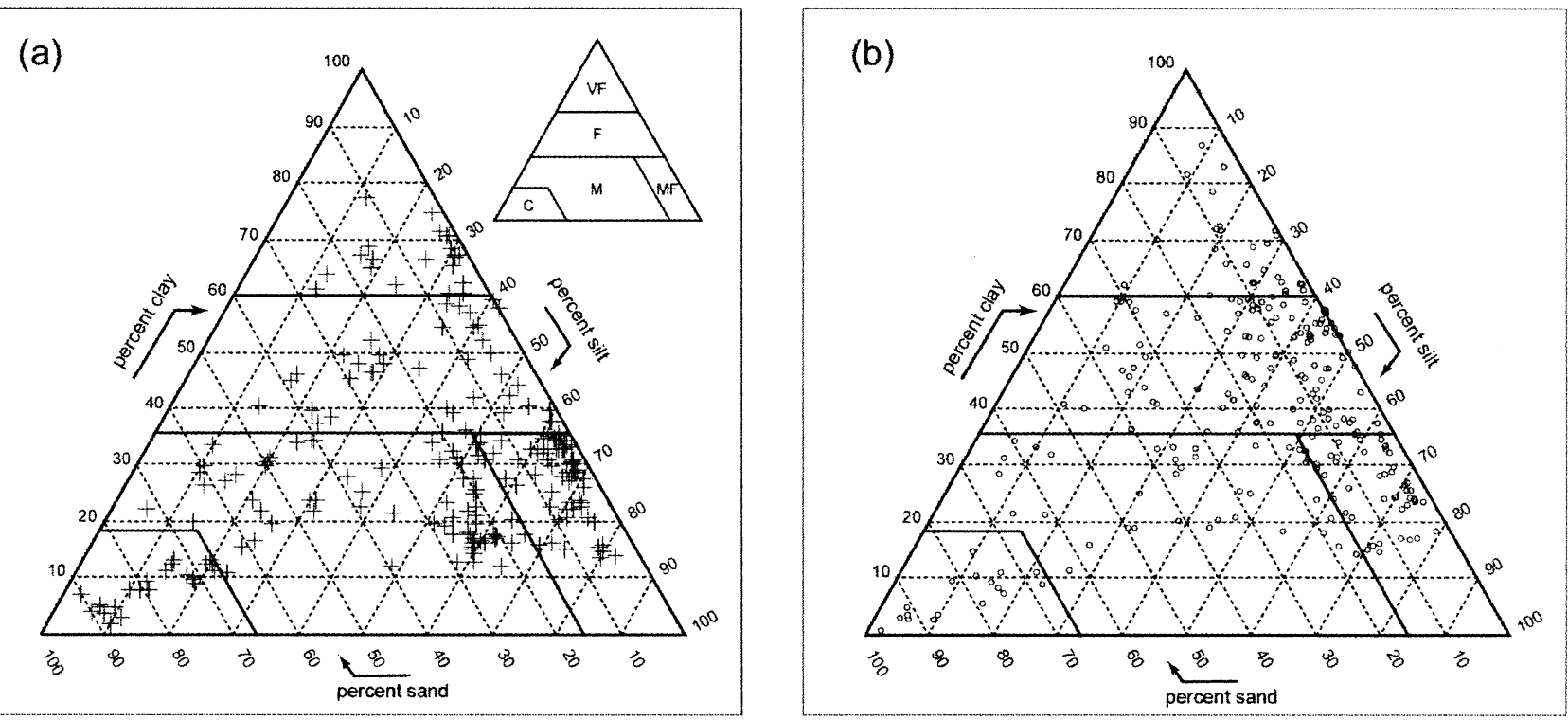

Figure 1. Texture of the horizons used to derive the class pedotransfer functions (a) and of those used to test their validity (b). For texture codings, see Materials section. 
Table 2. Characteristics of the horizons used to derive the class of pedotransfer functions and of those used to test their validity.

\begin{tabular}{|c|c|c|c|c|c|c|c|c|c|c|c|c|c|c|c|}
\hline & & \multicolumn{3}{|c|}{ Particle size distribution (\%) } & \multirow{2}{*}{$\begin{array}{l}\text { Organic } \\
\text { carbon } \\
\left(\mathrm{g} \mathrm{kg}^{-1}\right)\end{array}$} & \multirow{2}{*}{$\begin{array}{l}\mathrm{CaCO}_{3} \\
\left(\mathrm{~g} \mathrm{~kg}^{-1}\right)\end{array}$} & \multirow{2}{*}{$\begin{array}{c}\text { CEC } \\
\left(\mathrm{cmol}_{\mathrm{c}}\right. \\
\left.\mathrm{kg}^{-1}\right)\end{array}$} & \multirow{2}{*}{$\begin{array}{c}D_{b}^{c} \\
\left(\mathrm{~g} \mathrm{~cm}^{3}\right)\end{array}$} & \multicolumn{7}{|c|}{ Gravimetric water content $W_{\log (-h)}\left(\mathrm{g} \mathrm{g}^{-1}\right)$} \\
\hline & & $<2 \mu \mathrm{m}$ & $2-50 \mu \mathrm{m}$ & $0.05-2 \mathrm{~mm}$ & & & & & $W_{1.0}$ & $W_{1.5}$ & $W_{2.0}$ & $W_{2.5}$ & $W_{3.0}$ & $W_{3.5}$ & $W_{4.2}$ \\
\hline \multicolumn{16}{|c|}{ Horizons used to derive the class pedotransfer functions $(n=219)$} \\
\hline & mean & 31.3 & 44.1 & 24.6 & 5.6 & 13 & 16.0 & 1.59 & 0.237 & 0.228 & 0.216 & 0.198 & 0.176 & 0.156 & 0.128 \\
\hline & SD & 17.0 & 21.3 & 24.7 & 4.2 & 61 & 7.8 & 0.15 & 0.067 & 0.068 & 0.069 & 0.069 & 0.069 & 0.071 & 0.058 \\
\hline & $\min$ & 1.9 & 2.8 & 0.2 & 0.4 & 0 & 0.8 & 1.15 & 0.083 & 0.072 & 0.047 & 0.033 & 0.029 & 0.021 & 0.008 \\
\hline & $\max$ & 77.5 & 82.1 & 90.1 & 21.8 & 466 & 39.2 & 1.88 & 0.473 & 0.463 & 0.454 & 0.435 & 0.424 & 0.380 & 0.295 \\
\hline \multicolumn{16}{|c|}{ Horizons used to derive the class pedotransfer functions by class of texture } \\
\hline Very fine & mean & 66.8 & 25.0 & 8.2 & 6.0 & - & 27.3 & 1.37 & 0.362 & 0.360 & 0.347 & 0.331 & 0.309 & 0.287 & 0.239 \\
\hline$(n=22)$ & SD & 4.4 & 7.6 & 7.9 & 0.5 & - & 6.1 & 0.17 & 0.080 & 0.076 & 0.071 & 0.067 & 0.059 & 0.056 & 0.037 \\
\hline & $\min$ & 60.5 & 11.9 & 1.3 & 0.1 & - & 13.4 & 1.15 & 0.179 & 0.186 & 0.182 & 0.173 & 0.166 & 0.173 & 0.162 \\
\hline & $\max$ & 77.5 & 35.2 & 27.0 & 2.2 & - & 36.0 & 1.85 & 0.465 & 0.463 & 0.447 & 0.435 & 0.424 & 0.367 & 0.295 \\
\hline Fine & mean & 45.5 & 39.0 & 15.5 & 5.3 & - & 24.6 & 1.55 & 0.262 & 0.255 & 0.246 & 0.233 & 0.219 & 0.204 & 0.173 \\
\hline \multirow{3}{*}{$(n=42)$} & SD & 7.3 & 13.4 & 12.9 & 4.3 & - & 6.2 & 0.13 & 0.068 & 0.061 & 0.060 & 0.058 & 0.055 & 0.053 & 0.036 \\
\hline & $\min$ & 35.1 & 13.6 & 0.2 & 1.5 & - & 6.9 & 1.24 & 0.154 & 0.164 & 0.152 & 0.129 & 0.129 & 0.117 & 0.111 \\
\hline & $\max$ & 59.3 & 62.4 & 45.9 & 18.0 & - & 39.2 & 1.81 & 0.473 & 0.463 & 0.454 & 0.420 & 0.412 & 0.380 & 0.282 \\
\hline \multirow{4}{*}{$\begin{array}{l}\text { Medium fine } \\
(n=62)\end{array}$} & mean & 27.1 & 67.2 & 5.7 & 6.8 & - & 16.1 & 1.57 & 0.238 & 0.229 & 0.218 & 0.200 & 0.171 & 0.141 & 0.120 \\
\hline & SD & 6.4 & 6.2 & 3.4 & 4.2 & - & 5.7 & 0.08 & 0.018 & 0.017 & 0.015 & 0.015 & 0.021 & 0.025 & 0.025 \\
\hline & $\min$ & 13.7 & 53.9 & 1.3 & 1.5 & - & 5.4 & 1.39 & 0.194 & 0.194 & 0.180 & 0.170 & 0.124 & 0.084 & 0.068 \\
\hline & $\max$ & 35.0 & 82.1 & 14.8 & 15.1 & - & 25.1 & 1.74 & 0.280 & 0.264 & 0.251 & 0.234 & 0.219 & 0.183 & 0.163 \\
\hline \multirow{4}{*}{$\begin{array}{l}\text { Medium } \\
(n=69)\end{array}$} & mean & 23.2 & 43.1 & 33.7 & 4.3 & - & 13.2 & 1.67 & 0.205 & 0.197 & 0.185 & 0.168 & 0.147 & 0.125 & 0.101 \\
\hline & SD & 17.8 & 17.8 & 15.6 & 3.4 & - & 4.5 & 0.10 & 0.028 & 0.025 & 0.022 & 0.022 & 0.023 & 0.023 & 0.023 \\
\hline & $\min$ & 5.4 & 5.4 & 15.1 & 0.8 & - & 3.7 & 1.35 & 0.156 & 0.148 & 0.137 & 0.110 & 0.098 & 0.083 & 0.055 \\
\hline & $\max$ & 66.2 & 66.2 & 72.5 & 14.9 & - & 22.5 & 1.87 & 0.276 & 0.245 & 0.228 & 0.215 & 0.210 & 0.189 & 0.142 \\
\hline \multirow{4}{*}{$\begin{array}{l}\text { Coarse } \\
(n=24)\end{array}$} & mean & 8.4 & 13.4 & 78.2 & 6.3 & - & 4.6 & 1.72 & 0.169 & 0.149 & 0.120 & 0.099 & 0.078 & 0.066 & 0.050 \\
\hline & SD & 3.5 & 5.6 & 8.2 & 3.8 & - & 2.7 & 0.10 & 0.039 & 0.038 & 0.038 & 0.034 & 0.029 & 0.026 & 0.021 \\
\hline & $\min$ & 1.9 & 2.8 & 65.7 & 0.4 & - & 0.8 & 1.48 & 0.083 & 0.072 & 0.047 & 0.033 & 0.029 & 0.021 & 0.008 \\
\hline & $\max$ & 13.2 & 23.4 & 90.1 & 12.0 & - & 8.5 & 1.88 & 0.233 & 0.196 & 0.179 & 0.158 & 0.137 & 0.107 & 0.078 \\
\hline \multicolumn{16}{|c|}{ Horizons used to test the class pedotransfer functions $(n=221)$} \\
\hline & mean & 39.7 & 42.2 & 18.1 & 5.5 & 24 & 18.6 & 1.56 & - & - & - & 0.229 & - & - & 0.163 \\
\hline & SD & 18.3 & 18.7 & 18.4 & 5.4 & 67 & 8.6 & 0.15 & - & - & - & 0.076 & - & - & 0.067 \\
\hline & $\min$ & 0.5 & 5.9 & 0 & 0.8 & 0 & 1.2 & 1.20 & - & - & - & 0.022 & - & - & 0.013 \\
\hline & $\max$ & 86.7 & 79.4 & 97.4 & 4.0 & 544 & 47.4 & 1.90 & - & - & - & 0.395 & - & - & 0.310 \\
\hline
\end{tabular}

CEC: cation exchange capacity; $D_{b}^{c}$ : bulk density of clods; $W_{\log (-\mathrm{h})}$ : gravimetric water content at water potential, $h$, in $\mathrm{hPa}$.

loss. The dry bulk densities of 114 horizons $\left(D_{b}^{h}\right)$ were measured using $1236 \mathrm{~cm}^{3}$ cylinders. (These horizons are representative of the whole set of horizons used to derive the class PTFs.) Particle size distribution was measured using the pipette method after pre-treatment of samples with hydrogen peroxide and sodium hexametaphosphate (Robert \& Tessier 1974). The cation exchange capacity (CEC, in $\mathrm{cmol}_{\mathrm{C}} \mathrm{kg}^{-1}$ of oven-dried soil) was measured using the cobalt-hexamine trichloride method (Ciesielski \& Sterckeman 1997) and organic carbon by oxidation using excess potassium bichromate in sulphuric acid at $135^{\circ} \mathrm{C}$ (Baize 2000). Results were expressed by mass after drying at $105^{\circ} \mathrm{C}$. Clods $5-10 \mathrm{~cm}^{3}$ in volume were separated by hand from the stored samples. We measured the dry bulk density of the clods at field conditions $\left(D_{b}^{c}\right.$, in $\mathrm{cm}^{3} \mathrm{~g}^{-1}$ of oven-dried soil) by using the kerosene method (Monnier et al. 1973). Gravimetric water contents ( $W$, grams of water per gram of oven-dried soil) at the seven water potentials, $h$, viz. -10 $\left(W_{10}\right),-33\left(W_{33}\right),-100\left(W_{100}\right),-330\left(W_{330}\right),-1000\left(W_{1000}\right)$, $-3300\left(W_{3300}\right)$, and $-15000 \mathrm{hPa}\left(W_{15000}\right)$ were measured using pressure membrane or pressure plate apparatus. Clods were placed on a paste made of $<2 \mu \mathrm{m}$ particles of kaolinite to establish continuity of water between the clods and the membrane or the porous plate of the apparatus (Bruand et al. 1996). Specific water content and volume were expressed with respect to the dry mass of the sample after oven-drying at $105^{\circ} \mathrm{C}$ for 24 hours. Twelve to fifteen clods were used for each sample to determine the mean values of $W$ at the different values of water potential. For horizons used to test the class PTFs we measured $W_{330}$ and $W_{15000}$ only, using similar methodology.

\section{RESULTS AND DISCUSSION}

\section{The soils studied}

The mean composition of the horizons used to test the class PTFs was somewhat finer, since the clay content was $8.4 \%$ greater and the sand content was $6.5 \%$ smaller (CEC 2.6 $\mathrm{cmol}_{\mathrm{c}} \mathrm{kg}^{-1}$ greater) than in the set of horizons used to derive the class PTFs (Table 2). The mean organic carbon content 


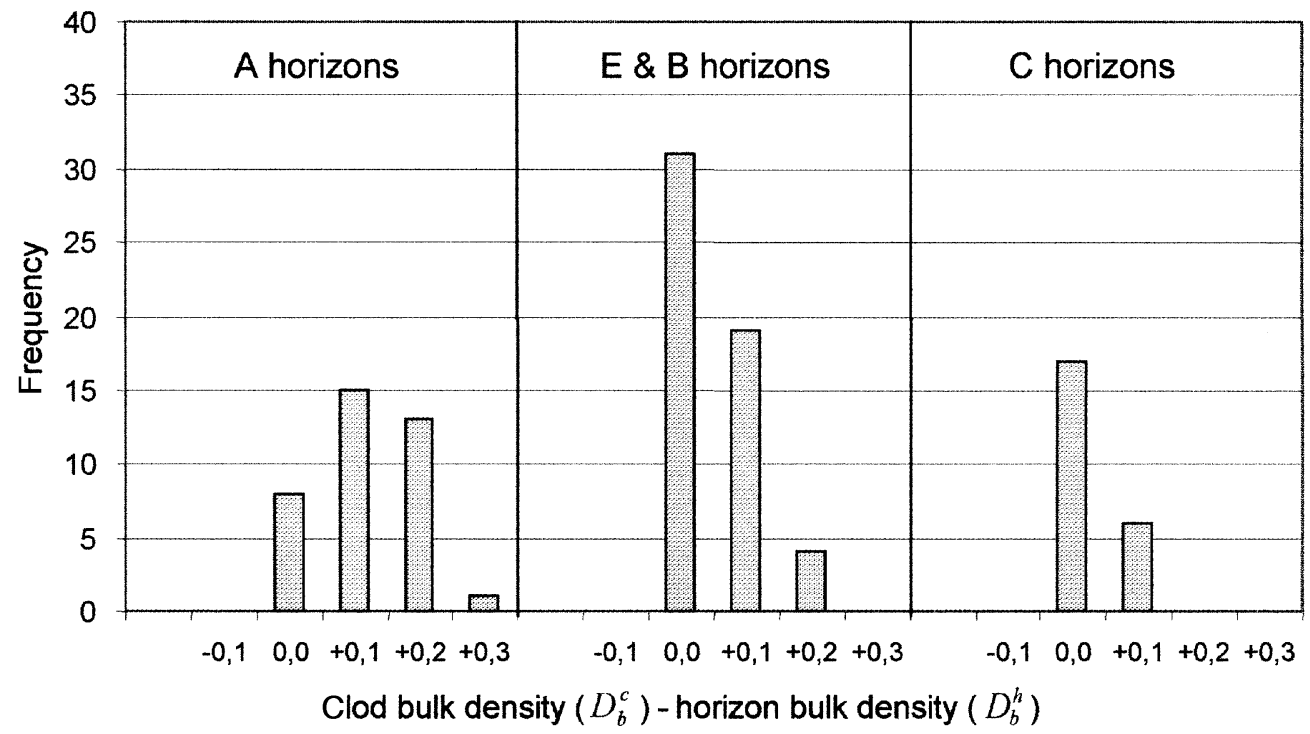

Figure 2. Distribution of horizons according to the difference between the bulk density measured on clods $\left(D_{b}^{c}\right)$ and the bulk density measured with large cylinders $\left(D_{b}^{h}\right)$. The classes showing $D_{b}^{c}-D_{b}^{h}$ are centred on $-0.1,0.0,+0.1,+0.2,+0.3$ and correspond to the intervals $\left.]-0.05,+0.05\right]$, ]+0.05, $+0.15],]+0.15,+0.25]$ and $]+0.25,+0.35]$

and the mean $D_{b}^{c}$ were similar for the two sets of horizons. The mean water content of the horizons used to test the class PTFs was $0.031 \mathrm{gg}^{-1}$ greater at -330 , and was $0.035 \mathrm{~g} \mathrm{~g}^{-1}$ greater at $-15000 \mathrm{hPa}$ because of the greater mean clay content (Table 2). Figure 2 shows that $D_{b}^{c}-D_{b}^{h}$ ranged from -0.05 to $+0.35 \mathrm{~g} \mathrm{~cm}^{-3}$ for $A$ horizons with a maximum for $+0.05<D_{b}^{c}-D_{b}^{h} \leqslant+0.15 \mathrm{~g} \mathrm{~cm}^{-3}$, from -0.05 to $+0.25 \mathrm{~g} \mathrm{~cm}^{-3}$ for $\mathrm{E}$ and $\mathrm{B}$ horizons with a maximum for $-0.05<D_{b}^{c}-D_{b}^{h} \leqslant+0.05 \mathrm{~g} \mathrm{~cm}^{-3}$ and from -0.05 to $+0.15 \mathrm{~g} \mathrm{~cm}^{-3}$ for $\mathrm{C}$ horizons with a maximum for $-0.05<D_{b}^{c}-D_{b}^{h} \leqslant+0.05 \mathrm{~g} \mathrm{~cm}^{-3}$. These differences between $D_{b}^{c}$ and $D_{b}^{h}$ are consistent with a decrease in the macroporosity with depth.

\section{Derivation of the class pedotransfer functions}

For horizons belonging to a class of texture, we computed the mean $W$ at the seven water potentials studied that define the class PTF for each texture class (Table 2). Then within each texture class we used $D_{b}^{c}$ to derive a new set of class PTFs. Unlike $D_{b}^{h}, D_{b}^{c}$ excludes the large pores that do not contribute to water retention and $D_{b}^{c}$ can be considered as an estimator of the effective volume of pores involved in the water retention properties. Thus for each texture class, we distributed the horizons according to $D_{b}^{c}$ and, for each of these classes combining texture and $D_{b}^{c}$, we computed the mean $W$ at the seven selected water potentials that defined the class PTF for the texture class and clod density considered (Table 3).

Performance analysis of the class pedotransfer functions In order to discuss the validity of the class PTFs proposed, we computed the mean error of prediction $\left(M E P_{\mathrm{w}}\right)$ and the standard deviation $\left(S D P_{\mathrm{w}}\right)$ of prediction as follows:

$$
\begin{gathered}
M E P_{\mathrm{w}}=\frac{1}{n} \sum^{n}\left(W_{\mathrm{p}}-W_{\mathrm{m}}\right), \\
S D P_{\mathrm{w}}=\left\{\frac{1}{n} \sum^{n}\left[\left(W_{\mathrm{p}}-W_{\mathrm{m}}\right)-M E P\right]^{2}\right\}^{1 / 2}
\end{gathered}
$$

where $W_{\mathrm{p}}$ is the predicted gravimetric water content, $W_{\mathrm{m}}$ is the measured gravimetric water content and $n$ is the number of horizons. The sign of $M E P_{\mathrm{w}}$ indicates whether the PTF overestimated (positive) or underestimated (negative) the water content, whereas $S D P_{\mathrm{w}}$ measures the precision of the predictions. To compare our results with the literature we computed also the root mean square error $\left(R M S E_{\theta}\right)$ as follows:

$$
R M S E_{\theta}=\left[\frac{1}{n} \sum^{n}\left(\theta_{\mathrm{p}}-\theta_{\mathrm{m}}\right)^{2}\right]^{1 / 2}
$$

where $\theta_{\mathrm{p}}$ and $\theta_{\mathrm{m}}$ are the predicted and measured volumetric water content, respectively. For horizons lacking a measured $D_{b}^{h}, \theta_{\mathrm{p}}$ and $\theta_{\mathrm{m}}$ were computed as follows:

$$
\begin{gathered}
\theta_{\mathrm{p}}=W_{\mathrm{p}} \times D_{b}^{c} \\
\theta_{\mathrm{m}}=W_{\mathrm{m}} \times D_{b}^{c}
\end{gathered}
$$

Thus the $R M S E_{\theta}$ that was computed using $D_{b}^{c}$ as an estimator of $D_{b}^{h}$ can be considered as an overestimation of the $R M S E_{\theta}$ of the measured $D_{b}^{h}$ because:

$$
D_{b}^{h} \leqslant D_{b}^{c}
$$

Validity of the class pedotransfer functions based on texture alone

Overall, the class PTFs derived using texture alone underestimated $W_{330}$ and $W_{15000}$ by 0.014 and $0.013 \mathrm{~g} \mathrm{~g}^{-1}$, respectively, and the precision was 0.038 and $0.031 \mathrm{~g} \mathrm{~g}^{-1}$, respectively (Table 4). The class PTFs underestimated $W_{330}$ 
Table 3. Water retained at different water potentials $(h)$ for each class of texture and bulk density of clods.

\begin{tabular}{|c|c|c|c|c|c|c|c|c|c|c|}
\hline \multirow{2}{*}{$\begin{array}{l}\text { Texture } \\
\text { class }\end{array}$} & \multirow{2}{*}{$\begin{array}{c}\text { Class of } \\
D_{b}^{c}\end{array}$} & & \multirow{2}{*}{$\begin{array}{c}D_{b}^{c} \\
\left(\mathrm{~g} \mathrm{~cm}^{-3}\right)\end{array}$} & \multicolumn{7}{|c|}{ Gravimetric water content $W_{\log (-h)}\left(\mathrm{g} \mathrm{g}^{-1}\right)$} \\
\hline & & & & $W_{1.0}$ & $W_{1.5}$ & $W_{2.0}$ & $W_{2.5}$ & $W_{3.0}$ & $W_{3.5}$ & $W_{4.2}$ \\
\hline \multirow[t]{12}{*}{ Very fine } & {$[1.2-1.3]$} & mean & 1.25 & 0.421 & 0.411 & 0.392 & 0.372 & 0.342 & 0.334 & 0.263 \\
\hline & & SD & 0.02 & 0.039 & 0.036 & 0.034 & 0.036 & 0.027 & 0.033 & 0.022 \\
\hline & & $\min$ & 1.22 & 0.341 & 0.346 & 0.337 & 0.327 & 0.301 & 0.280 & 0.235 \\
\hline & & $\max$ & 1.28 & 0.465 & 0.459 & 0.447 & 0.435 & 0.380 & 0.367 & 0.292 \\
\hline & ]1.3-1.4] & mean & 1.36 & 0.365 & 0.360 & 0.346 & 0.331 & 0.308 & 0.297 & 0.238 \\
\hline & & SD & 0.03 & 0.040 & 0.032 & 0.034 & 0.036 & 0.036 & 0.036 & 0.018 \\
\hline & & $\min$ & 1.32 & 0.293 & 0.310 & 0.281 & 0.260 & 0.240 & 0.228 & 0.199 \\
\hline & & $\max$ & 1.40 & 0.432 & 0.404 & 0.388 & 0.371 & 0.360 & 0.359 & 0.257 \\
\hline & ]1.4-1.5] & mean & 1.44 & 0.337 & 0.329 & 0.320 & 0.307 & 0.291 & 0.266 & 0.219 \\
\hline & & SD & 0.02 & 0.030 & 0.030 & 0.028 & 0.033 & 0.013 & 0.024 & 0.010 \\
\hline & & $\min$ & 1.42 & 0.316 & 0.308 & 0.300 & 0.284 & 0.282 & 0.249 & 0.212 \\
\hline & & $\max$ & 1.45 & 0.358 & 0.350 & 0.340 & 0.330 & 0.300 & 0.283 & 0.226 \\
\hline \multirow[t]{20}{*}{ Fine } & [1.3-1.4] & mean & 1.36 & 0.340 & 0.318 & 0.310 & 0.289 & 0.273 & 0.246 & 0.200 \\
\hline & & SD & 0.03 & 0.033 & 0.051 & 0.039 & 0.057 & 0.045 & 0.041 & 0.032 \\
\hline & & $\min$ & 1.33 & 0.301 & 0.276 & 0.280 & 0.236 & 0.234 & 0.217 & 0.167 \\
\hline & & $\max$ & 1.39 & 0.381 & 0.390 & 0.364 & 0.368 & 0.335 & 0.305 & 0.240 \\
\hline & ]1.4-1.5] & mean & 1.46 & 0.304 & 0.291 & 0.276 & 0.263 & 0.240 & 0.223 & 0.189 \\
\hline & & SD & 0.02 & 0.037 & 0.040 & 0.044 & 0.046 & 0.044 & 0.055 & 0.040 \\
\hline & & $\min$ & 1.43 & 0.268 & 0.249 & 0.227 & 0.212 & 0.182 & 0.153 & 0.139 \\
\hline & & $\max$ & 1.48 & 0.360 & 0.340 & 0.333 & 0.326 & 0.291 & 0.289 & 0.233 \\
\hline & ]1.5-1.6] & mean & 1.55 & 0.247 & 0.244 & 0.236 & 0.226 & 0.210 & 0.190 & 0.167 \\
\hline & & $\mathrm{SD}$ & 0.03 & 0.035 & 0.028 & 0.030 & 0.031 & 0.028 & 0.030 & 0.028 \\
\hline & & $\min$ & 1.51 & 0.154 & 0.164 & 0.152 & 0.129 & 0.129 & 0.117 & 0.111 \\
\hline & & $\max$ & 1.60 & 0.294 & 0.290 & 0.281 & 0.266 & 0.249 & 0.251 & 0.215 \\
\hline & ]1.6-1.7] & mean & 1.65 & 0.231 & 0.220 & 0.214 & 0.202 & 0.189 & 0.183 & 0.160 \\
\hline & & SD & 0.03 & 0.019 & 0.016 & 0.013 & 0.014 & 0.018 & 0.017 & 0.014 \\
\hline & & $\min$ & 1.62 & 0.202 & 0.199 & 0.197 & 0.185 & 0.172 & 0.164 & 0.134 \\
\hline & & $\max$ & 1.69 & 0.264 & 0.245 & 0.235 & 0.226 & 0.227 & 0.207 & 0.179 \\
\hline & ]1.7-1.8] & mean & 1.72 & 0.209 & 0.208 & 0.195 & 0.180 & 0.177 & 0.167 & 0.145 \\
\hline & & $\mathrm{SD}$ & 0.03 & 0.017 & 0.011 & 0.008 & 0.008 & 0.006 & 0.018 & 0.012 \\
\hline & & $\min$ & 1.71 & 0.181 & 0.197 & 0.182 & 0.172 & 0.171 & 0.160 & 0.132 \\
\hline & & $\max$ & 1.77 & 0.223 & 0.223 & 0.202 & 0.192 & 0.186 & 0.207 & 0.164 \\
\hline
\end{tabular}

$D_{b}^{c}$ : bulk density of clods; $W_{\log (-h)}$ : gravimetric water content at water potential, $h$, in hPa.

and $W_{15000}$ for all texture classes except for Coarse at $-330 \mathrm{hPa}$ and $-15000 \mathrm{hPa}$ water potential and for Medium Fine at $-15000 \mathrm{hPa}$ water potential. The greatest underestimation was recorded for Fine textures $\left(0.028 \mathrm{~g} \mathrm{~g}^{-1}\right.$ at $-330 \mathrm{hPa}$ and $0.023 \mathrm{~g} \mathrm{~g}^{-1}$ at $-15000 \mathrm{hPa}$ ) and the greatest overestimation was recorded with Coarse $\left(0.038 \mathrm{~g} \mathrm{~g}^{-1}\right.$ at $-330 \mathrm{hPa}$ and $0.019 \mathrm{~g} \mathrm{~g}^{-1}$ at $-15000 \mathrm{hPa}$ ) (Table 4). The least precise was the Fine class irrespective of the water potential, and the most precise at $-330 \mathrm{hPa}$ for the Medium Fine class and at $-15000 \mathrm{hPa}$ for the Coarse class.

\section{Validity of the class pedotransfer functions based on texture} and bulk density of clods

When the set of horizons was taken as a whole, results showed a smaller underestimation $\left(0.009 \mathrm{~g} \mathrm{~g}^{-1}\right.$ at $-330 \mathrm{hPa}$ and $0.011 \mathrm{~g} \mathrm{~g}^{-1}$ at $-15000 \mathrm{hPa}$ ) and a greater precision $\left(0.021 \mathrm{~g} \mathrm{~g}^{-1}\right.$ at $-330 \mathrm{hPa}$ and $0.022 \mathrm{~g} \mathrm{~g}^{-1}$ at $\left.-15000 \mathrm{hPa}\right)$ than with class PTFs based on texture alone (Table 4). Thus the estimation bias was reduced by 36 and $18 \%$ and the precision increased by 45 and $29 \%$ at $-330 \mathrm{hPa}$ and $-15000 \mathrm{hPa}$ water potential, respectively. When the bias was greater than $0.010 \mathrm{~g} \mathrm{~g}^{-1}$, analysis of the results for each texture class showed a decrease in the estimation bias, with the class PTFs based on texture and clod density. Precision for all textures increased at -330 and $-15000 \mathrm{hPa}$ water potential with the greatest increase in the Fine class. Results showed that $R M S E_{\theta}$ 's recorded at -330 and $-15000 \mathrm{hPa}$ water potential were smaller than with class PTFs based on texture alone (Table 4) and similar to those recorded with continuous PTFs (Wösten et al. 2001).

Proposed use of the class pedotransfer functions

Estimation of the water retention properties of a soil profile requires the component horizons to be identified. Then, 
Table 3. Continued.

\begin{tabular}{|c|c|c|c|c|c|c|c|c|c|c|}
\hline \multirow{2}{*}{$\begin{array}{l}\text { Texture } \\
\text { class }\end{array}$} & \multirow{2}{*}{$\begin{array}{c}\text { Class of } \\
D_{b}^{c}\end{array}$} & & \multirow{2}{*}{$\begin{array}{c}D_{b}^{c} \\
\left(\mathrm{~g} \mathrm{~cm}^{-3}\right)\end{array}$} & \multicolumn{7}{|c|}{ Gravimetric water content $W_{\log (-h)}\left(\mathrm{g} \mathrm{g}^{-1}\right)$} \\
\hline & & & & $W_{1.0}$ & $W_{1.5}$ & $W_{2.0}$ & $W_{2.5}$ & $W_{3.0}$ & $W_{3.5}$ & $W_{4.2}$ \\
\hline \multirow{12}{*}{$\begin{array}{l}\text { Medium } \\
\text { fine }\end{array}$} & \multirow[t]{4}{*}[1.4-1.5]{} & mean & 1.45 & 0.263 & 0.252 & 0.240 & 0.216 & 0.182 & 0.152 & 0.133 \\
\hline & & $\mathrm{SD}$ & 0.03 & 0.009 & 0.007 & 0.008 & 0.009 & 0.029 & 0.033 & 0.032 \\
\hline & & $\min$ & 1.41 & 0.247 & 0.239 & 0.229 & 0.204 & 0.126 & 0.090 & 0.079 \\
\hline & & $\max$ & 1.49 & 0.275 & 0.264 & 0.251 & 0.234 & 0.219 & 0.183 & 0.163 \\
\hline & \multirow[t]{4}{*}{] $1.5-1.6]$} & mean & 1.56 & 0.240 & 0.230 & 0.219 & 0.198 & 0.169 & 0.137 & 0.117 \\
\hline & & SD & 0.03 & 0.013 & 0.011 & 0.009 & 0.015 & 0.019 & 0.023 & 0.024 \\
\hline & & $\min$ & 1.51 & 0.219 & 0.213 & 0.205 & 0.170 & 0.132 & 0.096 & 0.068 \\
\hline & & $\max$ & 1.60 & 0.280 & 0.260 & 0.240 & 0.234 & 0.210 & 0.172 & 0.158 \\
\hline & \multirow[t]{4}{*}{ ]1.6-1.7] } & mean & 1.64 & 0.224 & 0.217 & 0.208 & 0.196 & 0.170 & 0.143 & 0.119 \\
\hline & & $\mathrm{SD}$ & 0.02 & 0.012 & 0.012 & 0.011 & 0.010 & 0.019 & 0.024 & 0.023 \\
\hline & & $\min$ & 1.60 & 0.201 & 0.195 & 0.190 & 0.178 & 0.125 & 0.084 & 0.074 \\
\hline & & $\max$ & 1.69 & 0.247 & 0.240 & 0.230 & 0.211 & 0.199 & 0.169 & 0.146 \\
\hline \multirow[t]{16}{*}{ Medium } & \multirow[t]{4}{*}[1.5-1.6]{} & mean & 1.57 & 0.230 & 0.219 & 0.201 & 0.177 & 0.149 & 0.133 & 0.113 \\
\hline & & SD & 0.02 & 0.009 & 0.014 & 0.013 & 0.022 & 0.026 & 0.027 & 0.020 \\
\hline & & $\min$ & 1.52 & 0.213 & 0.190 & 0.176 & 0.146 & 0.111 & 0.083 & 0.078 \\
\hline & & $\max$ & 1.60 & 0.246 & 0.240 & 0.220 & 0.213 & 0.188 & 0.179 & 0.142 \\
\hline & \multirow[t]{4}{*}{ ]1.6-1.7] } & mean & 1.65 & 0.212 & 0.205 & 0.193 & 0.173 & 0.146 & 0.117 & 0.092 \\
\hline & & SD & 0.03 & 0.009 & 0.019 & 0.019 & 0.023 & 0.026 & 0.024 & 0.019 \\
\hline & & $\min$ & 1.60 & 0.173 & 0.152 & 0.137 & 0.110 & 0.099 & 0.089 & 0.055 \\
\hline & & $\max$ & 1.70 & 0.241 & 0.232 & 0.221 & 0.215 & 0.210 & 0.189 & 0.128 \\
\hline & \multirow[t]{4}{*}{ ]1.7-1.8] } & mean & 1.75 & 0.184 & 0.177 & 0.171 & 0.161 & 0.149 & 0.129 & 0.105 \\
\hline & & SD & 0.03 & 0.015 & 0.014 & 0.013 & 0.011 & 0.013 & 0.016 & 0.022 \\
\hline & & $\min$ & 1.70 & 0.165 & 0.156 & 0.149 & 0.140 & 0.130 & 0.093 & 0.063 \\
\hline & & $\max$ & 1.79 & 0.209 & 0.201 & 0.190 & 0.181 & 0.168 & 0.155 & 0.133 \\
\hline & \multirow[t]{4}{*}{ ]1.8-1.9] } & mean & 1.84 & 0.168 & 0.162 & 0.155 & 0.147 & 0.143 & 0.129 & 0.098 \\
\hline & & SD & 0.03 & 0.010 & 0.008 & 0.007 & 0.007 & 0.014 & 0.024 & 0.031 \\
\hline & & $\min$ & 1.80 & 0.156 & 0.148 & 0.145 & 0.136 & 0.124 & 0.091 & 0.061 \\
\hline & & $\max$ & 1.87 & 0.187 & 0.172 & 0.163 & 0.155 & 0.161 & 0.154 & 0.141 \\
\hline \multirow[t]{12}{*}{ Coarse } & \multirow[t]{4}{*}[1.6-1.7]{} & mean & 1.65 & 0.191 & 0.168 & 0.127 & 0.110 & 0.086 & 0.069 & 0.054 \\
\hline & & $\mathrm{SD}$ & 0.02 & 0.032 & 0.022 & 0.019 & 0.019 & 0.018 & 0.020 & 0.017 \\
\hline & & $\min$ & 1.62 & 0.147 & 0.142 & 0.105 & 0.087 & 0.060 & 0.048 & 0.034 \\
\hline & & $\max$ & 1.68 & 0.233 & 0.196 & 0.158 & 0.140 & 0.112 & 0.094 & 0.076 \\
\hline & \multirow[t]{4}{*}{ ]1.7-1.8] } & mean & 1.74 & 0.160 & 0.144 & 0.110 & 0.088 & 0.069 & 0.057 & 0.049 \\
\hline & & $\mathrm{SD}$ & 0.03 & 0.048 & 0.050 & 0.052 & 0.043 & 0.036 & 0.030 & 0.006 \\
\hline & & $\min$ & 1.70 & 0.083 & 0.072 & 0.047 & 0.033 & 0.029 & 0.021 & 0.018 \\
\hline & & $\max$ & 1.78 & 0.201 & 0.196 & 0.179 & 0.158 & 0.137 & 0.107 & 0.078 \\
\hline & \multirow[t]{4}{*}{ ]1.8-1.9] } & mean & 1.85 & 0.164 & 0.152 & 0.139 & 0.122 & 0.099 & 0.089 & 0.069 \\
\hline & & SD & 0.03 & 0.015 & 0.017 & 0.019 & 0.014 & 0.019 & 0.010 & 0.006 \\
\hline & & $\min$ & 1.81 & 0.145 & 0.133 & 0.119 & 0.107 & 0.080 & 0.077 & 0.065 \\
\hline & & $\max$ & 1.88 & 0.178 & 0.172 & 0.156 & 0.143 & 0.128 & 0.099 & 0.078 \\
\hline
\end{tabular}

$D_{b}^{c}$, bulk density of centimetric clods; $W_{\log (-h)}$, gravimetric water content at water potential, $h$, in hPa.

from the texture class in the FAO triangle for each horizon and using either the PTFs based on texture or texture $+D_{b}^{c}$, the water retention properties can be estimated (Figure 3). 1. When $D_{b}^{c}$ is unknown (i.e. not measured and cannot be inferred from $D_{b}^{h}$ or from any other horizon characteristics) and if the horizon characteristics known are within the range of horizons used to derive the class PTFs (Table 2), we can use the class PTFs based on texture alone. Then, by selecting the appropriate $D_{b}^{h}$ proposed in Appendix I, values of $\theta$ are available. If $D_{b}^{h}$ were not measured, it might be inferred from other horizon characteristics or from other soil data. Finally, parameters of van Genuchten's model (1980) that were computed for each class PTF using the RETC code (van Genuchten et al. 1991) are shown in Appendix I and the corresponding curves in Figure 4.

2. When $D_{b}^{c}$ is known (i.e. measured or inferred from $D_{b}^{h}$ or from other horizon characteristics) and if the horizon characteristics known are within the range of horizons used to derive the class PTFs (Table 2), we can use the class PTFs based on texture and bulk density of clods that are shown in Appendix II to provide values of $\theta$. 
Table 4. Validity of the class pedotransfer functions derived after stratification by texture alone and after stratification by texture and clod bulk density.

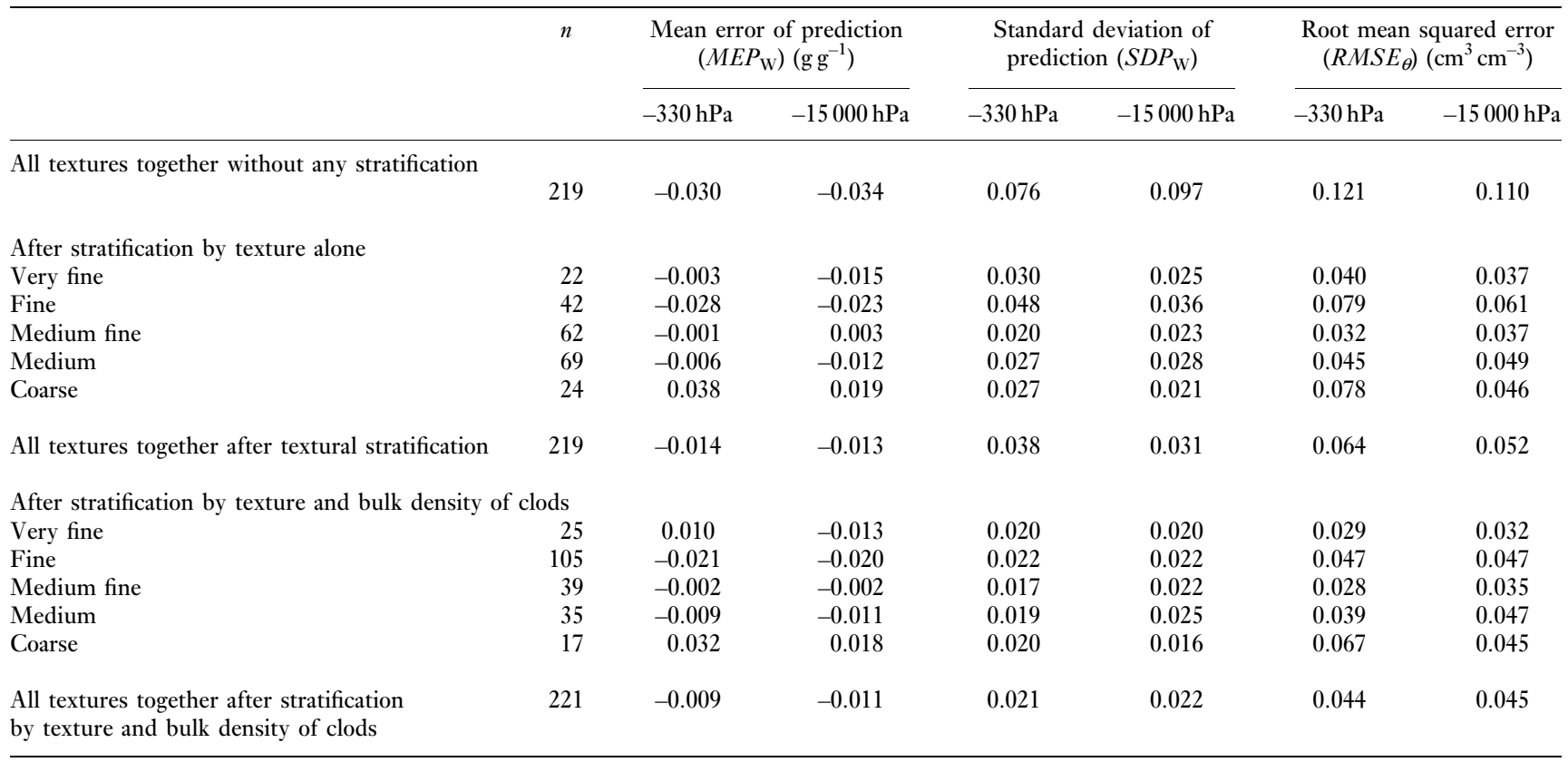

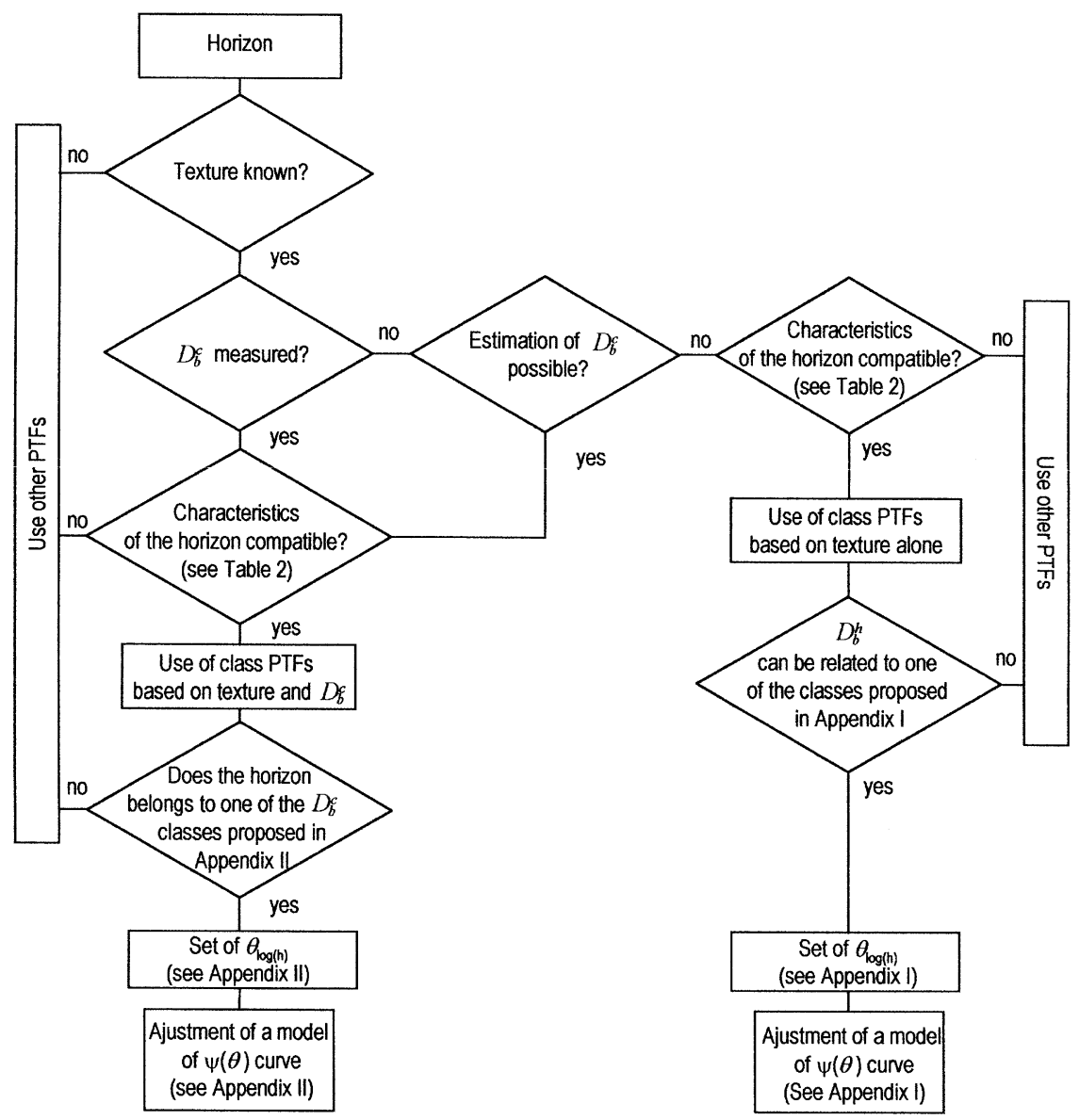

Figure 3. Flowchart illustrating the estimation method of the water retention properties for a soil horizon. 


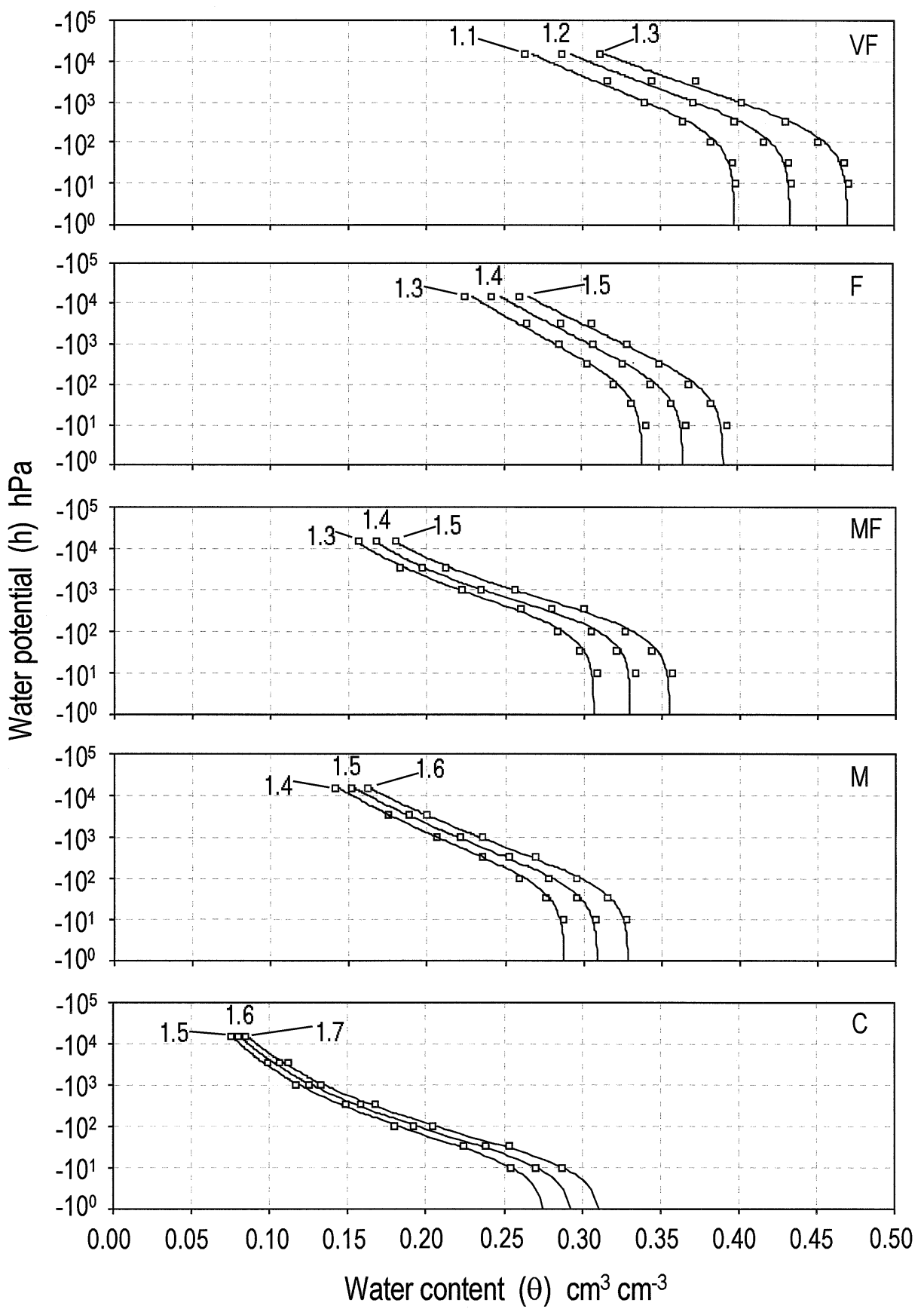

Figure 4. Water retention curves for different values of horizon bulk density $\left(D_{b}^{h}\right)$ corresponding to the class PTFs based on texture alone and computed using van Genuchten's model (1980) (see Appendix I). For texture codings, see Materials section.

Finally, parameters of the van Genuchten's model (1980) that were computed for each class PTF as in point 1 are shown in Appendix II.

\section{CONCLUSION}

Our results showed that PTFs based on texture and clod bulk density provide estimates of gravimetric water content of soil horizons at seven water potentials ranging from -10 to
$-15000 \mathrm{hPa}$ with an accuracy that is (i) greater than with class PTFs based on texture alone, and (ii) similar to the estimation accuracy recorded with continuous PTFs. As a consequence, the lack of interest in class PTFs should be reconsidered to bridge the gap between basic soil data which is available and missing hydraulic properties (Wösten et al. 2001), particularly when pertinent soil characteristics can be derived from the data available. For example, the clod bulk density, which is more pertinent than the horizon bulk 
density but not usually available in most databases, can be derived by combining data such as bulk density of the soil, structure and macroporosity development. Volumetric water content, which is required for applications in agronomy and hydrology, was derived from the estimated gravimetric water content using the horizon bulk density and parameters of the van Genuchten water retention curve model that we computed for each class PTF. Finally, because of the significance of clay mineralogy and pedogenesis (Bruand \& Tessier 2000), further development of class PTFs should take into account other criteria such as clay mineralogy, type of parent material or type of pedogenesis.

\section{REFERENCES}

Baize D 2000. Guide des analyses en pédologie. INRA Paris.

Bastet G Bruand A Voltz M Bornand M \& Quétin P 1999. Performance of available pedotransfer functions for predicting the water retention properties of French soils. In: MTh. van Genuchten \& F.J. Leij, eds, Characterization and measurement of the hydraulic properties of unsaturated porous media. Proceedings of the International Workshop, Riverside, California, October 22-24, 1997 pp 981-992.

Bruand A Duval O Gaillard H Darthout R \& Jamagne M 1996. Variabilité des propriétés de rétention en eau des sols:importance de la densité apparente. Etude et Gestion des Sols 3, 27-40.

Bruand A \& Tessier D 2000. Water retention properties of the clay in soils developed on clayey sediments: Significance of parent material and soil history. European Journal of Soil Science 51, 679- 688.

Ciesielski H \& Sterckeman T 1997. Determination of cation exchange capacity and exchangeable cations in soils by means of cobalt hexamine trichloride. Effects of experimental conditions. Agronomie 17, 1-7.

Leij FJ Alves WJ van Genuchten MTh Williams JR 1999. The UNSODA unsaturated soil hydraulic database. In: MTh van Genuchten \& FJ Leij, eds, Characterization and measurement of the hydraulic properties of unsaturated porous media. Proceedings of the International Workshop, Riverside, California, October 22-24, 1997 pp 1269-1281.

Lilly A Wösten JHM Nemes A Le Bas C 1999. The development and use of the HYPRES database in Europe. In: MTh van Genuchten \& FJ Leij, eds, Characterization and measurement of the hydraulic properties of unsaturated porous media. Proceedings of the International Workshop, Riverside, California, October 22-24, 1997 pp 1283-1204.

Van Genuchten MTh 1980. A closed-form equation for predicting the hydraulic conductivity of unsaturated soil. Soil Science Society of America Journal 44, 892-898.

Van Genuchten MTh Leij FJ \& Yates SR 1991. The RETC code for quantifying the hydraulic functions of unsaturated soil. USDA, US Salinity Laboratory, Riverside CA. United States Environmental Protection Agency, document EPA/600/2-91/065.

ISSS Working Group RB 1998. World reference base for soil resources: introduction, eds, J.A. Deckers, F.O. Nachtergaele \& O.C. Spaargaren, 1st edition. International Society of Soil Science. ISRIC-FAO-ISSSAcco Leuven Belgium.

Misnamy B McBratney AB \& Bristow KL 1999. Comparison of different approaches to the development of pedotransfer functions for waterretention curves. Geoderma 93, 225-253.

Monnier G Stengel P \& Fiès JC 1973. Une méthode de mesure de la densité apparente de petits agglomérats terreux. Application à l'analyse des systèmes de porosité du sol. Annales Agronomiques 24, 533-545.

Rawls WJ Ahuja LR Brakensiek DL 1992. Estimating soil hydraulic properties from soils data. In: MTh van Genuchten \& FJ Leij, eds, Indirect methods for Estimating the Hydraulic Properties of Unsaturated Soils. Proceedings of the International Workshop, Riverside, California, October 11-13, 1989, 329-340.

Robert M \& Tessier D 1974. Méthode de préparation des argiles des sols pour les études minéralogiques. Annales Agronomiques 25, 859-882.

Vereecken H Maes J Feyen J \& Darius P 1989. Estimating the soil moisture retention characteristics from texture, bulk density and carbon content. Soil Science 148, 389-403.

Wösten JHM Finke PA \& Jansen MJW 1995. Comparison of class and continuous pedotransfer functions to generate soil hydraulic characteristics. Geoderma 66, 227-237.

Wösten JHM Lilly A Nemes A \& Le Bas C 1999. Development and use of a database of hydraulic properties of European soils. Geoderma 90, $169-185$.

Wösten JHM Pachepsky YA \& Rawls WJ 2001. Pedotransfer functions: bridging the gap between available basic soil data and missing soil hydraulic characteristics. Journal of Hydrology 251, 123-150.

Received August 2002, accepted after revision April 2003 
Appendix I. Volumetric water contents at the different water potentials using the class pedotransfer functions based on texture alone (see Table 2) and parameters of the van Genuchten's (1980) model adjusted on the volumetric water contents.

\begin{tabular}{|c|c|c|c|c|c|c|c|c|c|c|c|c|c|c|}
\hline \multirow[t]{2}{*}{ Texture class } & \multirow[t]{2}{*}{$\overline{D_{b}^{c}}$} & \multirow[t]{2}{*}{$D_{b}^{h}$} & \multicolumn{7}{|c|}{ Volumetric water content, $\theta_{\log (-h)}\left(\mathrm{cm}^{3} \mathrm{~cm}^{-3}\right)$} & \multicolumn{5}{|c|}{ Parameters of van Genuchten's model } \\
\hline & & & $\theta_{1.0}$ & $\theta_{1.5}$ & $\theta_{2.0}$ & $\theta_{2.5}$ & $\theta_{3.0}$ & $\theta_{3.5}$ & $\theta_{4.2}$ & $\theta_{\mathrm{s}}$ & $\theta_{\mathrm{r}}$ & $n$ & $\alpha$ & $R^{2}$ \\
\hline \multirow[t]{3}{*}{ Very fine } & 1.37 & 1.3 & 0.471 & 0.468 & 0.451 & 0.430 & 0.402 & 0.386 & 0.311 & 0.470 & 0.0004 & 1.0934 & 0.0046 & 0.992 \\
\hline & & 1.2 & 0.434 & 0.432 & 0.416 & 0.397 & 0.371 & 0.356 & 0.287 & 0.433 & 0.0006 & 1.0939 & 0.0045 & 0.993 \\
\hline & & 1.1 & 0.398 & 0.396 & 0.382 & 0.364 & 0.340 & 0.316 & 0.263 & 0.397 & 0.0007 & 1.0942 & 0.0044 & 0.992 \\
\hline \multirow[t]{3}{*}{ Fine } & 1.55 & 1.5 & 0.393 & 0.383 & 0.369 & 0.350 & 0.329 & 0.306 & 0.260 & 0.391 & 0.0008 & 1.0793 & 0.0089 & 0.991 \\
\hline & & 1.4 & 0.367 & 0.357 & 0.344 & 0.326 & 0.307 & 0.286 & 0.242 & 0.365 & 0.0008 & 1.0792 & 0.0091 & 0.989 \\
\hline & & 1.3 & 0.341 & 0.332 & 0.320 & 0.303 & 0.285 & 0.265 & 0.225 & 0.339 & 0.0010 & 1.0794 & 0.0092 & 0.991 \\
\hline \multirow[t]{3}{*}{ Medium fine } & 1.57 & 1.5 & 0.357 & 0.344 & 0.327 & 0.300 & 0.256 & 0.212 & 0.180 & 0.355 & 0.0929 & 1.2414 & 0.0068 & 0.997 \\
\hline & & 1.4 & 0.333 & 0.321 & 0.305 & 0.280 & 0.234 & 0.197 & 0.168 & 0.330 & 0.1103 & 1.2991 & 0.0062 & 0.997 \\
\hline & & 1.3 & 0.309 & 0.298 & 0.283 & 0.260 & 0.222 & 0.183 & 0.156 & 0.307 & 0.0833 & 1.2487 & 0.0066 & 0.997 \\
\hline \multirow[t]{3}{*}{ Medium } & 1.67 & 1.6 & 0.328 & 0.315 & 0.296 & 0.269 & 0.235 & 0.200 & 0.162 & 0.329 & 0.0009 & 1.1357 & 0.0121 & 0.999 \\
\hline & & 1.5 & 0.308 & 0.296 & 0.278 & 0.252 & 0.221 & 0.188 & 0.152 & 0.309 & 0.0005 & 1.1345 & 0.0122 & 0.999 \\
\hline & & 1.4 & 0.287 & 0.276 & 0.259 & 0.235 & 0.206 & 0.175 & 0.141 & 0.288 & 0.0007 & 1.1361 & 0.0119 & 0.999 \\
\hline \multirow[t]{3}{*}{ Coarse } & 1.72 & 1.7 & 0.287 & 0.253 & 0.204 & 0.168 & 0.133 & 0.112 & 0.085 & 0.313 & 0.0320 & 1.2378 & 0.0677 & 0.999 \\
\hline & & 1.6 & 0.270 & 0.238 & 0.192 & 0.158 & 0.125 & 0.106 & 0.080 & 0.294 & 0.0305 & 1.2379 & 0.0680 & 0.999 \\
\hline & & 1.5 & 0.254 & 0.224 & 0.180 & 0.149 & 0.117 & 0.099 & 0.075 & 0.277 & 0.0285 & 1.2390 & 0.0675 & 0.999 \\
\hline
\end{tabular}

$\overline{D_{b}^{c}}$, mean bulk density of clods within every texture class; $D_{b}^{c}$, Bulk density of the horizon inferred from $\overline{D_{b}^{c}} ; \theta_{\log (-h)}$, volumetric water content at water potential, $h$, in $\mathrm{hPa}$. 
Appendix II. Volumetric water contents at the different water potentials using the class pedotransfer functions based on texture and bulk density (see Table 2) and parameters of the van Genuchten's (1980) model adjusted on the volumetric water contents.

\begin{tabular}{|c|c|c|c|c|c|c|c|c|c|c|c|c|c|c|}
\hline \multirow{2}{*}{$\begin{array}{l}\text { Texture } \\
\text { class }\end{array}$} & \multirow[t]{2}{*}{ Class of $D_{b}^{c}$} & \multirow[t]{2}{*}{$D_{b}^{h}$} & \multicolumn{7}{|c|}{ Volumetric water content, $\theta_{\log (-h)}\left(\mathrm{cm}^{3} \mathrm{~cm}^{-3}\right)$} & \multicolumn{5}{|c|}{ Parameters of van Genuchten's model } \\
\hline & & & $\theta_{1.0}$ & $\theta_{1.5}$ & $\theta_{2.0}$ & $\theta_{2.5}$ & $\theta_{3.0}$ & $\theta_{3.5}$ & $\theta_{4.2}$ & $\theta_{\mathrm{s}}$ & $\theta_{\mathrm{r}}$ & $n$ & $\alpha$ & $R^{2}$ \\
\hline \multirow[t]{6}{*}{ Very fine } & \multirow[t]{2}{*}[1.2-1.3]{} & 1.25 & 0.531 & 0.514 & 0.490 & 0.465 & 0.428 & 0.418 & 0.329 & 0.527 & 0.0100 & 1.0849 & 0.0098 & 0.964 \\
\hline & & 1.15 & 0.484 & 0.473 & 0.451 & 0.428 & 0.393 & 0.384 & 0.303 & 0.481 & 0.0001 & 1.0868 & 0.0083 & 0.966 \\
\hline & \multirow[t]{2}{*}{ ]1.3-1.4] } & 1.35 & 0.493 & 0.486 & 0.467 & 0.447 & 0.416 & 0.401 & 0.321 & 0.488 & 0.0002 & 1.0930 & 0.0042 & 0.971 \\
\hline & & 1.25 & 0.456 & 0.450 & 0.433 & 0.414 & 0.385 & 0.371 & 0.298 & 0.452 & 0.0006 & 1.0923 & 0.0043 & 0.973 \\
\hline & \multirow[t]{2}{*}{ ]1.4-1.5] } & 1.45 & 0.489 & 0.477 & 0.464 & 0.445 & 0.422 & 0.386 & 0.318 & 0.481 & 0.0001 & 1.1055 & 0.0028 & 0.987 \\
\hline & & 1.35 & 0.455 & 0.444 & 0.432 & 0.415 & 0.393 & 0.359 & 0.296 & 0.448 & 0.0001 & 1.1066 & 0.0027 & 0.988 \\
\hline \multirow[t]{10}{*}{ Fine } & \multirow[t]{2}{*}[1.3-1.4]{} & 1.35 & 0.459 & 0.429 & 0.419 & 0.390 & 0.369 & 0.332 & 0.270 & 0.449 & 0.0007 & 1.0975 & 0.0088 & 0.977 \\
\hline & & 1.25 & 0.425 & 0.398 & 0.388 & 0.361 & 0.341 & 0.325 & 0.250 & 0.415 & 0.0010 & 1.0927 & 0.0086 & 0.952 \\
\hline & \multirow[t]{2}{*}{ ]1.4-1.5] } & 1.45 & 0.441 & 0.422 & 0.400 & 0.381 & 0.348 & 0.323 & 0.274 & 0.441 & 0.0002 & 1.0802 & 0.0194 & 0.992 \\
\hline & & 1.35 & 0.410 & 0.393 & 0.373 & 0.355 & 0.324 & 0.301 & 0.255 & 0.410 & 0.0007 & 1.0811 & 0.0180 & 0.993 \\
\hline & \multirow[t]{2}{*}{ ]1.5-1.6] } & 1.55 & 0.383 & 0.378 & 0.366 & 0.350 & 0.326 & 0.295 & 0.259 & 0.383 & 0.0006 & 1.0854 & 0.0062 & 0.999 \\
\hline & & 1.45 & 0.358 & 0.353 & 0.342 & 0.328 & 0.305 & 0.276 & 0.242 & 0.358 & 0.0001 & 1.0864 & 0.0059 & 0.999 \\
\hline & \multirow[t]{2}{*}{ ]1.6-1.7] } & 1.65 & 0.381 & 0.363 & 0.353 & 0.333 & 0.312 & 0.302 & 0.264 & 0.384 & 0.0003 & 1.0558 & 0.0377 & 0.986 \\
\hline & & 1.55 & 0.358 & 0.341 & 0.332 & 0.313 & 0.293 & 0.284 & 0.248 & 0.361 & 0.0002 & 1.0560 & 0.0367 & 0.986 \\
\hline & \multirow[t]{2}{*}{ ]1.7-1.8] } & 1.75 & 0.366 & 0.364 & 0.341 & 0.315 & 0.310 & 0.292 & 0.263 & 0.377 & 0.0005 & 1.0518 & 0.0560 & 0.981 \\
\hline & & 1.65 & 0.345 & 0.343 & 0.322 & 0.297 & 0.292 & 0.276 & 0.239 & 0.352 & 0.0001 & 1.0583 & 0.0333 & 0.974 \\
\hline \multirow[t]{6}{*}{ Medium fine } & \multirow[t]{2}{*}[1.4-1.5]{} & 1.45 & 0.381 & 0.365 & 0.348 & 0.313 & 0.264 & 0.220 & 0.193 & 0.377 & 0.1402 & 1.3325 & 0.0068 & 0.997 \\
\hline & & 1.35 & 0.355 & 0.340 & 0.324 & 0.292 & 0.246 & 0.205 & 0.180 & 0.352 & 0.1309 & 1.3332 & 0.0068 & 0.997 \\
\hline & \multirow[t]{2}{*}{] $1.5-1.6]$} & 1.55 & 0.372 & 0.357 & 0.340 & 0.307 & 0.262 & 0.212 & 0.181 & 0.369 & 0.1002 & 1.2653 & 0.0068 & 0.996 \\
\hline & & 1.45 & 0.348 & 0.334 & 0.318 & 0.287 & 0.245 & 0.199 & 0.170 & 0.345 & 0.0943 & 1.2631 & 0.0070 & 0.997 \\
\hline & \multirow[t]{2}{*}{ ]1.6-1.7] } & 1.65 & 0.370 & 0.358 & 0.343 & 0.323 & 0.281 & 0.236 & 0.196 & 0.367 & 0.0435 & 1.1707 & 0.0056 & 0.996 \\
\hline & & 1.55 & 0.347 & 0.336 & 0.322 & 0.304 & 0.264 & 0.222 & 0.185 & 0.344 & 0.0583 & 1.1875 & 0.0053 & 0.996 \\
\hline \multirow[t]{8}{*}{ Medium } & \multirow[t]{2}{*}[1.5-1.6]{} & 1.55 & 0.356 & 0.340 & 0.312 & 0.274 & 0.231 & 0.206 & 0.175 & 0.360 & 0.1125 & 1.2472 & 0.0170 & 0.999 \\
\hline & & 1.45 & 0.334 & 0.318 & 0.292 & 0.257 & 0.216 & 0.193 & 0.164 & 0.338 & 0.1036 & 1.2423 & 0.0176 & 0.999 \\
\hline & \multirow[t]{2}{*}{ ]1.6-1.7] } & 1.65 & 0.350 & 0.338 & 0.319 & 0.286 & 0.241 & 0.193 & 0.152 & 0.350 & 0.0120 & 1.1862 & 0.0078 & 0.999 \\
\hline & & 1.55 & 0.329 & 0.318 & 0.299 & 0.268 & 0.226 & 0.181 & 0.143 & 0.329 & 0.0088 & 1.1820 & 0.0082 & 0.999 \\
\hline & \multirow[t]{2}{*}{ ]1.7-1.8] } & 1.75 & 0.322 & 0.310 & 0.299 & 0.282 & 0.261 & 0.226 & 0.184 & 0.317 & 0.0002 & 1.1231 & 0.0049 & 0.992 \\
\hline & & 1.65 & 0.304 & 0.292 & 0.282 & 0.266 & 0.246 & 0.212 & 0.173 & 0.299 & 0.0005 & 1.1245 & 0.0048 & 0.992 \\
\hline & ]1.8-1.9] & 1.85 & 0.311 & 0.300 & 0.287 & 0.272 & 0.265 & 0.239 & 0.181 & 0.302 & 0.0003 & 1.1276 & 0.0026 & 0.959 \\
\hline & & 1.75 & 0.294 & 0.284 & 0.271 & 0.257 & 0.250 & 0.226 & 0.172 & 0.286 & 0.0009 & 1.1240 & 0.0028 & 0.959 \\
\hline Coarse & [1.6-1.7] & 1.65 & 0.315 & 0.277 & 0.210 & 0.182 & 0.142 & 0.114 & 0.089 & 0.352 & 0.0334 & 1.2429 & 0.0843 & 0.996 \\
\hline & & 1.55 & 0.296 & 0.260 & 0.197 & 0.171 & 0.133 & 0.121 & 0.084 & 0.339 & 0.0328 & 1.2286 & 0.1123 & 0.993 \\
\hline & ]1.7-1.8] & 1.75 & 0.280 & 0.252 & 0.193 & 0.154 & 0.121 & 0.100 & 0.086 & 0.294 & 0.0695 & 1.4180 & 0.0339 & 0.999 \\
\hline & & 1.65 & 0.264 & 0.238 & 0.193 & 0.154 & 0.100 & 0.094 & 0.081 & 0.272 & 0.0711 & 1.5179 & 0.0257 & 0.996 \\
\hline & ]1.8-1.9] & 1.85 & 0.303 & 0.281 & 0.257 & 0.226 & 0.183 & 0.165 & 0.128 & 0.310 & 0.0008 & 1.1434 & 0.0304 & 0.996 \\
\hline & & 1.75 & 0.287 & 0.266 & 0.243 & 0.214 & 0.173 & 0.156 & 0.121 & 0.294 & 0.0008 & 1.1435 & 0.0307 & 0.996 \\
\hline
\end{tabular}

$D_{b}^{c}$, bulk density of clods; $D_{b}^{h}$, bulk density of the horizon inferred from $D_{b}^{c}$. 